$\xi=-1$

\title{
Design and Comparison of Microstrip Patch Antennas for Wireless Body Area Network
}

\author{
S Krishna Veni ${ }^{1}$, G S K Gayatridevi ${ }^{2}$ \\ ${ }^{I}$ Dept. of ECE, School of Engineering, GVP college for Degree and PG courses. Rushikonda, Visakhapatnam, Andhra Pradesh, India \\ ${ }^{2}$ Dept. of ECE, Malla Reddy Engineering College. Hyderabad, Telangana, India \\ *Corresponding author E-mail:veni.sahukara@gmail.com
}

\begin{abstract}
The Body Area Network (BAN) is a wireless technology in combination with wearables. It is a monitoring system which is mainly used in health care, children tracking, in car-assistance and sports science etc. For wireless monitoring and continuous data transfer, an antenna needs to be integrated with the Body Area Network. This paper explains the different designs of microstrip patch antennas which operates at $2.4 \mathrm{GHz}$ and are more suitable for BAN. The simulation results in terms of return loss, gain and radiation pattern are presented.
\end{abstract}

Keywords: Body Area Network, HFSS, microstrip.

\section{Introduction}

This BAN consists of an array of devices or sensors are classified across the body, technology wirelessly to a body-connected central tube, to be connected to an off body receivment. Wearable antenna plays key role for developing the wearable computer systems and smart clothing, which help in rapid progress in wireless communications [1]. In [2], yang et.al proposed an E-shaped antenna by incorporating two parallel slots in order to increase the bandwidth. The ISM band is an Industrial Scientific Medical band. There are lots of applications in wireless Communication field in the ISM band around the frequency $2.4 \mathrm{GHz}$ [3]. In [4], the author proposed micro strip patch antenna array with DGS and simulated results for $7.642 \mathrm{GHz}$.

Specific Absorption Rate simulations are reported [5]. In [6], In this scheme, the linear pattern of linear elements with identical elements is designed to be designed in such a way that by selecting the location of $\mathrm{X}$ and the amplitude of the current (Ii) and the current phase Ii> Decrease sunflower (SLL) levels. The algorithm has been developed based on continuously inherited algorithms. The design software is responsible for calculating the values of the intervals, amplitudes and phase of the currents to determine the number of specified elements $\mathrm{i}=1,2, \ldots \mathrm{N}$, the maximum level of the lateral petals (SLL) Reduce the threshold. The requirements of wearable antenna for modern applications are low cost, light weight, almost maintenance-free and comfortable on body [7-8].

The Yagi-Uda antenna is one of the most successful RF antenna design for high directivity applications. Not only has the gain of the Yagi-Uda antenna important, as it enabled better levels of signal to noise ratio to be achieved. In the present work, different micro strip patch antennas are proposed which are operating in the ISM frequency band.

The paper is organized as follows; Second section represents the design of an antenna, third section describes the comparison between different designs. Finally, the conclusion is presented in the fourth section.

\section{Design of an antenna}

The following drawing shows the different patch designs to get better radiation characteristics.

\subsection{E-Shape Patch Antenna}

The micro strip patch is of copper material and E in shape. The dielectric substrate used here is of Rogers RT/Durroid 5880, whose dielectric constant is $\epsilon_{Y}=2.2$ and co-axial feed at the center is used here to feed the antenna. The geometry of the design is as shown in Figure 1.

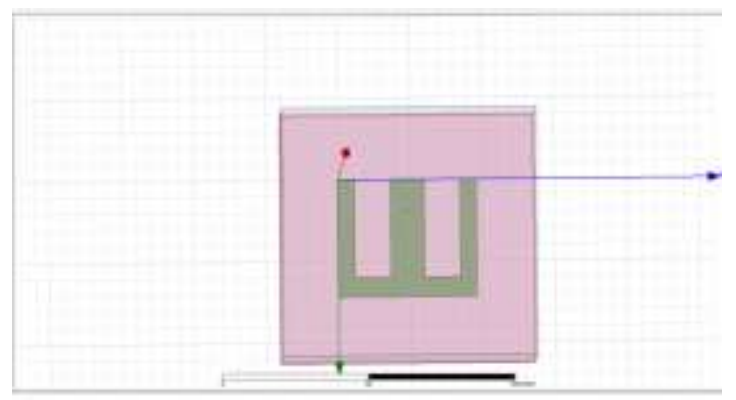

Figure 1:. E-Shape Patch Antenna

The simulation results of E shape patch antenna using HFSS are as shown below.

\subsubsection{Return Loss}

Generally for any antenna return loss is in between $-\infty$ to $-9.54 \mathrm{~dB}$. In this E shape design the return loss is $-14.79 \mathrm{~dB}$, so it is feasible for practical applications. 


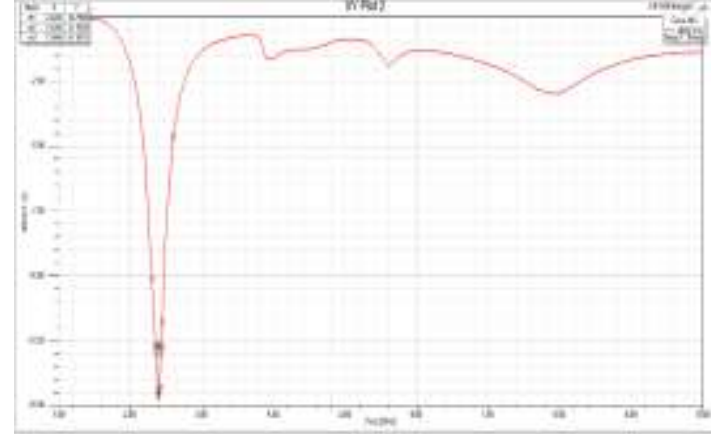

Figure 2:. Return Loss of E shape patch antenna

\subsubsection{Gain}

Determining the position of the user in wireless networks is important and has wide applications, but it has challenges, because factors such as measurement noise and error associated with indirect wave propagation paths (NLOS) cause a lot of error in position estimation. . One way to deal with the NLOS error is to detect and mitigate its impact in the position estimation process. This thesis first introduces a NLOS detection method using received signal strength measurements (RSS).

We get the gain for $\mathrm{E}$ shape patch antenna nearly equal to $7.0927 \mathrm{~dB}$.

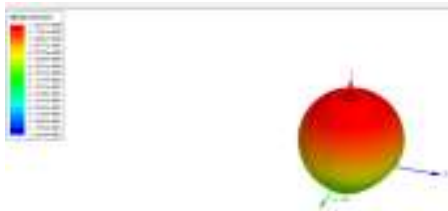

Figure 3:. Gain of E shape patch antenna

Figure 3. Gain of E shape patch antenna

\subsubsection{Radiation Pattern}

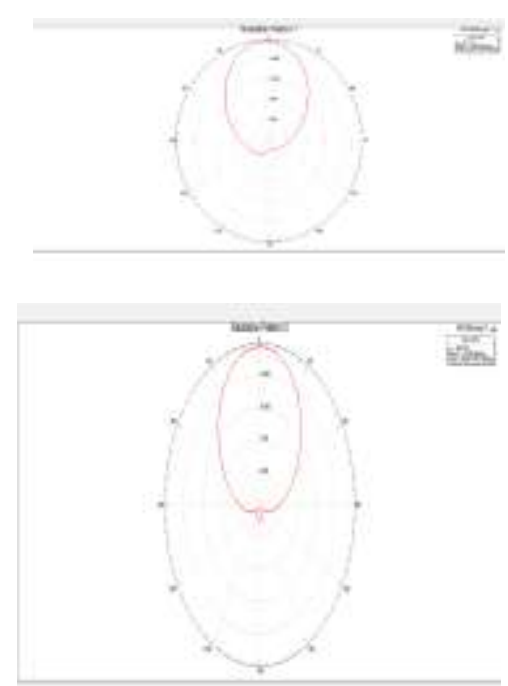

Figure 5:. Radiation Pattern (H Plane)

\subsection{H Shape Patch Antenna}

The design of the $\mathrm{H}$ shaped patch antenna is shown in the figure 6 . The co-axial feed is positioned at the corner of the design is responsible for the excitation of resonant frequency. Using
FR4_epoxy, with relative permeability $(\mathrm{Er}=4.4)$ is taken as a substrate.

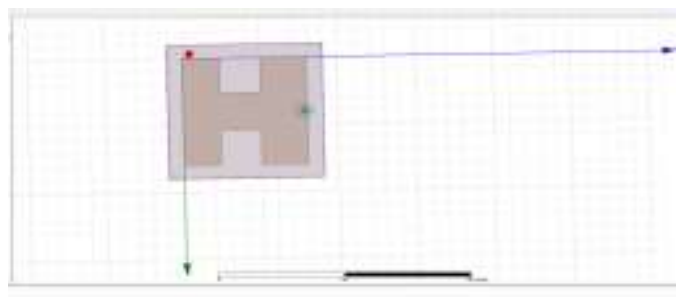

Figure 6:. H Shape Patch Antenna

\subsubsection{Return Loss}

The return loss obtained for the $\mathrm{H}$ shape patch design shown in this paper is $-24.15 \mathrm{~dB}$

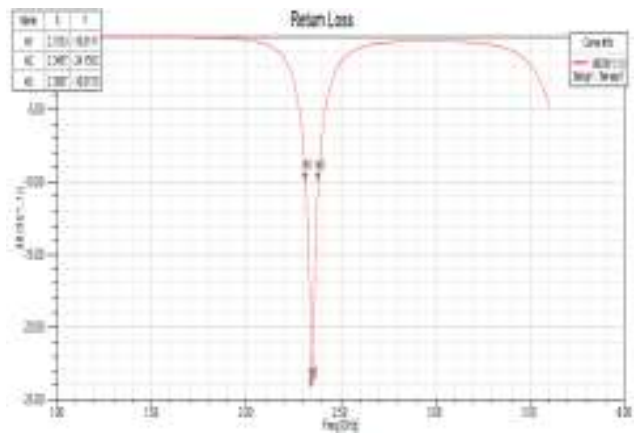

Figure 7:. Return loss of H Shape Design

\subsubsection{Gain}

The gain for $\mathrm{H}$ shape patch antenna is nearly equal to $7.7772 \mathrm{~dB}$.
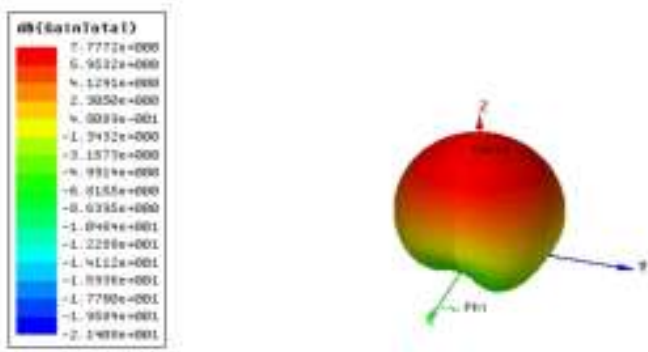

Figure 8:. Gain of H Shape Design

\subsubsection{Radiation Pattern}

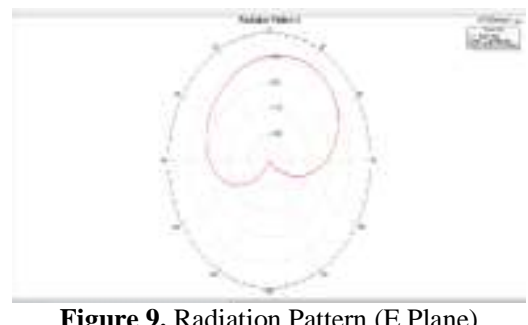

Figure 9. Radiation Pattern (E Plane)

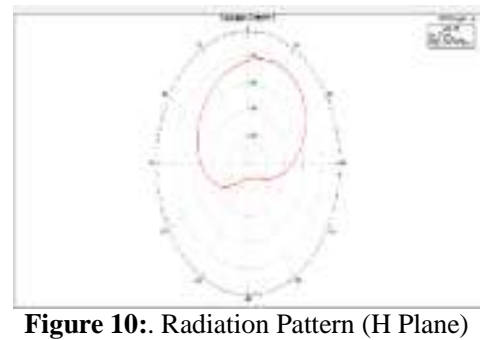




\subsection{Yagi Circular Patch Antenna}

In this design, substrate is circular in shape. Figure11 shows the design of Yagi Circular Patch Antenna. A simple, flexible light weight Yagi Circular Patch Antenna with two directors and two reflectors having two extra coupling elements using FR-4 as a substrate is designed to operate at $2.4 \mathrm{GHz}$. The mechanical properties of the FR-4 make the antenna element flexible with permittivity $\epsilon_{y}=4.4$, for flexibility purpose the thickness is made 1.6 $\mathrm{mm}$. These properties make FR-4 very attractive to be used as substrates for the fabrication of antennas in applications having low loss, reduced bill of materials, preserving the electromagnetic performance.

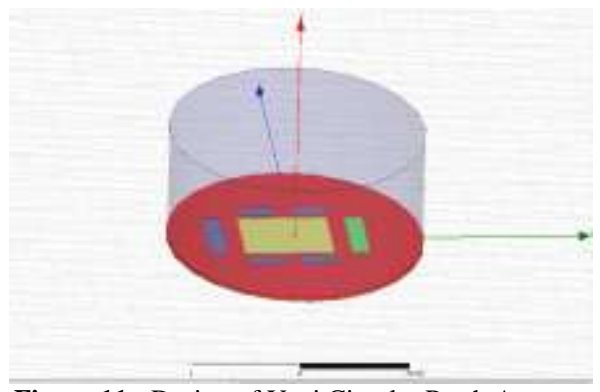

Figure 11:. Design of Yagi Circular Patch Antenna

Following table gives the specifications for Yagi Uda Antenna parameters:

\begin{tabular}{|c|c|c|}
\hline S.No & Parameter & Value \\
\hline 1 & Operating frequency & $2.45 \mathrm{GHz}$ \\
\hline 2 & Dielectric constant & 4.4 \\
\hline 3 & Substrate thickness & $1.6 \mathrm{~mm}$ \\
\hline 4 & Substrate radius & $36 \mathrm{~mm}$ \\
\hline 5 & Driven element dimension & $30 \mathrm{~mm} \mathrm{X} \mathrm{25mm}$ \\
\hline 6 & Director dimension & $10 \mathrm{~mm} \mathrm{X} \mathrm{5mm}$ \\
\hline 7 & Reflector dimension & $10 \mathrm{~mm} \mathrm{X} \mathrm{5mm}$ \\
\hline 8 & $\begin{array}{c}\text { Extra coupling element di- } \\
\text { mension }\end{array}$ & $25 \mathrm{mmX5mm}$ \\
\hline 9 & Ground thickness & $0.5 \mathrm{~mm}$ \\
\hline
\end{tabular}

\subsubsection{Return Loss}

The return loss obtained for the design of Yagi Circular shape patch shown in this paper is $-20.79 \mathrm{~dB}$.

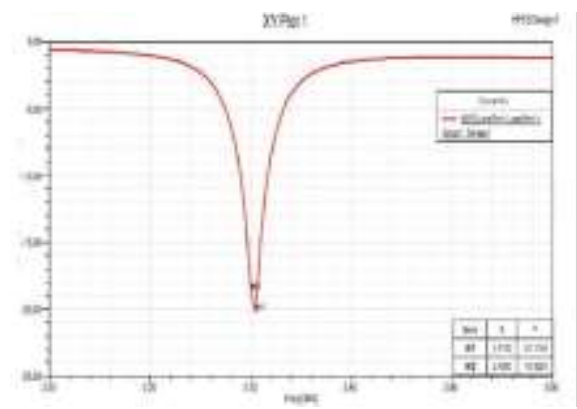

Figure 12:. Return Loss of Yagi Circular Patch Antenna

\subsubsection{Gain}

The gain for this Yagi Design with two directors and two reflectors is nearly equal to $9.3036 \mathrm{~dB}$
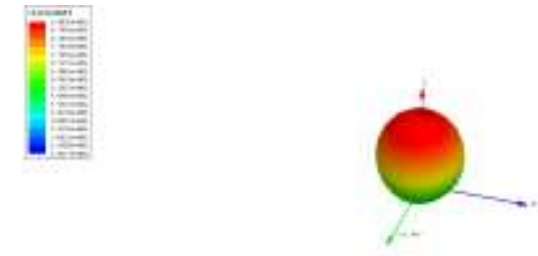

Figure 13. Gain of Yagi Circular Patch Antenna

\subsubsection{Radiation Pattern}

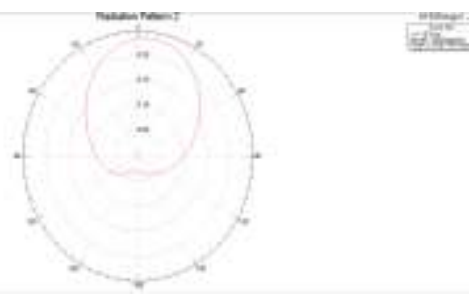

Figure 14:. Radiation Pattern (E Plane)

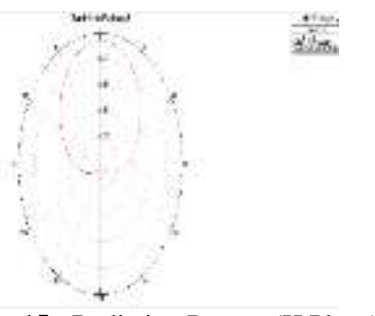

Figure 15:. Radiation Pattern (H Plane)

\section{Comparison Table}

Table 2:. Performance parameters of Yagi, E \& H Patch Antennas at 2.4 $\mathrm{GHz}$

\begin{tabular}{|c|c|c|}
\hline Designed antenna & Return loss (dB) & Gain (dB) \\
\hline Yagi-Circular patch & -20.79 & 9.3036 \\
\hline H-Shape patch & -24.15 & 7.7772 \\
\hline E-Shape patch & -14.79 & 7.0927 \\
\hline
\end{tabular}

\section{Conclusion}

The proposed design of the circular Yagi patch antenna using HFSS software possesses the good return loss of $-20.79 \mathrm{~dB}$ and higher gain of $9.30 \mathrm{~dB}$ compared to the E- shape patch and $\mathrm{H}$ shape patch which have the return losses of -14.79 and 24.15 ,gain of 7.07 and 7.77 respectively. From the above comparison of all three different shapes of patches, it is observed that the Yagi patch with circular ground substrate gives the better parameters that are suitable for BAN and Telemedicine applications.

\section{References}

[1] C.A. Balanis, Antenna theory analysis and design, 3rd edition, john Wiley and Son's Inc. New York, 2005.

[2] F. Yang, Xue-Xia Zhang, Xiaoning Ye and Y. Rahmat-Samii, "Wide-band E-shaped patch antennas for wireless communications," in IEEE Transactions on Antennas and Propagation, vol. 49, no. 7, pp. 1094-1100, Jul 2001.

[3] Ahmed El Oualkadi, "Design of Rectangular Ring Patch Antenna for ISM Band at $2.45 \mathrm{GHz}$ ", Recent Advances in Circuits, Systems, Telecommunications and Control ISBN: 978-960-474-341-4.

[4] Bharadwaj R, Design of MicroStrip Patch Antenna Array Using DGS for ISM Band Applications. Glob J Res Rev. 2017, 4:1.

[5] S. Yan, P. J. Soh and G. A. E. Vandenbosch, "Wearable Dual-Band Magneto-Electric Dipole Antenna for WBAN/WLAN Applica- 
tions," in IEEE Transactions on Antennas and Propagation, vol. 63, no. 9 , pp. 4165-4169, Sept. 2015.

[6] TanishNarang; Shubhangijain; "Microstrip Patch Antenna- A Historical Perspective of the Development", Conference on Advances in Communication and Control Systems 2013 (CAC2S 2013).

[7] P. Byuvol, L. Gabsalikhova, I. Makarova, E. Mukhametdinov, G Sadygova, "Improving the Branded Service Network Efficiency based on its Functioning Evaluation", Astra Salvensis, Supplement No. 2, p. 373, 2017.

[8] Azad N., Ghandvar P., Rahimi Z., "Online Search Behaviour of Customers in Shoe Market”, Astra Salvensis, Supplement No. 2, p. $793,2017$. 